\title{
SENTIDOS NA REDE: SOBRE A DOCÊNCIA
}

Senses and the Electronic Network: About Teaching

\author{
Juliana Aparecida Possidônio* \\ Lucília Maria Abrahão e Sousa** \\ Soraya Maria Romano Pacífico***
}

\begin{abstract}
RESUMO
Incitados por reflexões acerca do sujeito discursivo na sua relação com os sentidos e a rede eletrônica, buscamos, neste trabalho, sob as referências teóricas da Análise de Discurso (AD) de "linha francesa", erigir uma discussão sobre questões relativas ao ciberespaço, tais como a materialidade linguística que o distingue, a memória discursiva que o caracteriza e a galáxia de sentidos que o seu uso, cada vez maior, como lugar de produção, constituição e circulação do discurso, faz circular. As contribuições teóricas de Michel Pêcheux e de outros grandes teóricos que a partir dele se orientam, são aqui evocadas, com o intuito de pensar a $\mathrm{AD}$ como um dispositivo teórico e analítico que nos possibilita compreender discursivamente $o$ ciberespaço e os sujeitos a ele "conectados". Propomo-nos ainda a análise do discurso de sujeitos-professores no espaço da rede eletrônica, como comentário a uma publicação sobre a docência na educação infantil, com a finalidade de conhecer os sentidos por eles produzidos (ou reproduzidos, pensando então o sujeito na sua interpelação ideológica e no seu atravessamento pelo inconsciente) e perceber a maneira como tais sujeitos utilizam o ciberespaço para discursivizar a respeito de suas concepções e de sua atuação profissional.
\end{abstract}

Palavras-chave: discurso; linguagem; ciberespaço.

$\begin{array}{ll}* & \text { FFCLRP-USP. } \\ * * & \text { FFCLRP-USP. } \\ * * * & \text { FFCLRP-USP. }\end{array}$

Revista Letras, Curitiba, n. 92 p. 153-170, JUL/DEZ. 2015. ISSN 2236-0999 (VERSÃo ELETRÔNICA) 


\begin{abstract}
Spurred by reflections on the discursive subject in its relationship with the senses and the electronic network, we seek, in this work, under the theoretical references of Discourse Analysis (AD) of "French line", to start a discussion of issues related to cyberspace, such as the materiality of language that distinguishes it, discursive memory that characterizes it, galaxy senses and their use, growing, as a place of production, creation and circulation of discourse. The theoretical contributions of Michel Pêcheux, and other major theorists, are evoked here, with the purpose of about thinking $\mathrm{AD}$ as a theoretical and analytical device that enables us to understand discursively cyberspace and subjects "connected" to it. We propose also a discourse analysis of subject-teachers within the electronic network, as a comment to a publication about teaching in early childhood education, in order to know the meanings they produced (or reproduced, considering the subject in the ideological interpellation and also considering the influence of the unconscious) and to realize how these individuals use cyberspace to discourse about their conceptions and their professional performance.
\end{abstract}

Keywords: discourse; language; cyberspace.

\title{
1. Nosso INí́cio
}

O referencial teórico da Análise de Discurso (AD), enquanto lugar de reflexão sobre o discurso, o sujeito e os sentidos, se constitui como origem de nossas inquietações desde nosso primeiro movimento de pesquisa ${ }^{1}$, mergulhando-nos em questões a respeito da relação dos sujeitos-escolares - dada nossa posição discursiva de sujeitos-professores - com os sentidos e com as práticas de leitura e de escrita. É, pois, um olhar para as questões da linguagem, despido da paráfrase, enquanto lugar de cristalização de sentidos, e ancorado na descoberta de que os sentidos são tecidos a cada novo momento, a cada novo texto, a cada novo dizer, que nos inspira enquanto sujeitos-pesquisadores e nos levam a querer compreender cada vez mais o modo como os sujeitos-alunos e sujeitos-professores se relacionam com os sentidos e se valem do discurso como espaço de poder dizer.

Configurando-se historicamente como um espaço de repetição de conteúdos, de imposição de sentidos e de homogeneidade de interpretações, é

1 Nossa primeira investigação científica se deu no intuito de analisar a produção discursiva de sujeitos-alunos do ensino fundamental a respeito do tema família, buscando conhecer os sentidos por eles produzidos e compreender a relação dos mesmos com a prática de escrita, enquanto lugar de emergência da subjetividade (POSSIDÔNIO, 2011). 
que o ensino da língua, ao longo da trajetória escolar da grande maioria dos sujeitos-alunos se apresenta: é a imagem de um professor como voz absoluta, gerindo os sentidos possíveis à nossa inserção na língua, ao nosso falar, ao nosso interpretar, ao nosso ler e ao nosso escrever que vem sempre à mente ao recordarmos de nossas aulas de Língua Portuguesa. Falar corretamente, escrever sem erros gramaticais ou ortográficos, ler fluentemente, interpretar e repetir os significados inerentes ao texto: seriam apenas essas as metas a serem alcançadas por um sujeito, em relação ao uso de sua língua?

Nosso contato com estudos recentes sobre as práticas de leitura, intepretação e escrita (ROMÃO; PACÍFICO, 2006; PACÍFICO; ROMÃO, 2007) e com experiências de professores engajados com os mesmos referenciais teóricos que nos movimentam, nos permite responder negativamente a tal questão e, mais que isso, nos permite pensar as práticas de leitura e escrita enquanto espaço a ser marcado pela polissemia, pela multiplicidade de sentidos, pela subjetividade do sujeito, por sua identificação e produção de sentidos, como lugar de assunção da autoria e de argumentação.

Pensando então as práticas de linguagem a partir de um ponto de vista discursivo, que considera o sujeito em sua incompletude, tendo existência a partir da sua relação com o discurso e os sentidos, é que nos aventuramos nos estudos do sujeito discursivo no contexto da rede eletrônica. Incitados por um dizer corriqueiro que se remete a esse espaço - na verdade, ao ciberespaço - como "um lugar de tudo poder dizer", marcado pela movência e pela possibilidade do sentido vir sempre a ser outro, bem diferente daquele da escola que descrevíamos, é que surge em nós o desejo de pensar os sujeitos-escolares na sua relação com a rede. Num contexto social em que sujeitos-alunos são discursivizados como esquivos à leitura e à escrita e, ainda mais, em que os próprios sujeitos-professores se apresentam resistentes à produção de discursos escritos (ASSEF; PACÍFICO, 2012), nos deparamos, no espaço discursivo da rede eletrônica, com esses mesmos sujeitos enunciando e demarcando o ciberespaço como um lugar possível para se identificar e produzir sentidos.

Querendo então compreender os fios que tecem a textualidade eletrônica e as condições de produção desse espaço discursivo, é que esse artigo toma corpo, na intenção de analisar os movimentos do sujeito, cindido e atravessado pelo ideológico e pelo inconsciente, que tem como constitutiva a ilusão de ser a origem de seu dizer e que busca na rede eletrônica o espaço de poder produzir sentidos do qual ele tanto tem sede: espaço esse que pudemos pensar, ao longo desse texto, para além dessa "democratização" à informação e ao "direto à fala". Propomo-nos, dessa forma, a refletir sobre a materialidade linguística da rede, a memória discursiva que a caracteriza, a galáxia de sentidos que o seu uso, cada vez maior, como lugar 
de produção, constituição e circulação do discurso, faz circular, além dos conceitos-chave da teoria de Análise de Discurso, retomando as reflexões de Michel Pêcheux e de grandes teóricos que a partir dele se guiam, pensando a $\mathrm{AD}$ como um dispositivo teórico e analítico que nos permite compreender discursivamente o ciberespaço e os sujeitos a ele conectados. Pretendemos ainda casar as reflexões sobre o discurso e o ciberespaço com nosso atual objeto de pesquisa (POSSIDÔNIO, 2013), qual seja, o discurso de sujeitos-professores, analisando o discurso por eles produzido no espaço da rede eletrônica, como comentário a uma publicação sobre a docência na educação infantil, querendo então conhecer os sentidos por eles produzidos e perceber a maneira como tais sujeitos utilizam o ciberespaço para discursivizar a respeito de suas concepções e de sua atuação profissional.

\section{O TEMPO E O ESPAÇO DA REDE: ALGUMAS REFLEXÕES SOBRE OS SENTIDOS DO CIBERESPAÇO}

Pensar a rede eletrônica para além do "código binário", de um ponto de vista técnico, mas de uma perspectiva de linguagem: eis os sentidos dos nossos estudos e a nossa ambição nesse trabalho. Mas o que dizer sobre o ciberespaço e a galáxia de sentidos por ele produzida? o advento da internet veio problematizar questões que antes estavam em zonas muito estabelecidas no campo da produção, constituição e circulação do discurso: apresentando-se como um lugar de acesso a toda e qualquer informação, como um lugar possível ao dizer, como um espaço permeado por transformações e mais transformações, como um lugar caracterizado pela polifonia, pela pluralidade, pela flutuação e fluidez contínua, a rede eletrônica vem questionar, nesse contexto, o papel histórico da escola como única fonte de criação e como único lugar de acesso ao saber.

Para além disso, o dilúvio característico do ciberespaço nos inunda em uma nova configuração de tempo e de espaço: aquela grande distância, característica do impresso, dos primeiros equipamentos, das primeiras máquinas de falar, é agora encurtada. Há, pois, um encurtamento das "distâncias" físicas, de um jeito em que o lá e o cá se (con)fundem. O tempo de fazer e chegar lá, o tempo de inventar e emitir, o tempo de produzir e de circular a informação, falando no ponto de vista da Análise de Discurso, o tempo de produção, constituição e circulação do discurso, era um tempo muito longo, e a internet veio assoprar essa lentidão, colocando nessa instância um agora, um aqui, um ao mesmo tempo, o tempo todo, em potência avassaladora.

O espaço deixou de ser obstáculo - basta uma fração de segundo para conquistá-lo (...) onde quer que estejamos em determinado momento, não podemos evitar de saber que poderíamos estar em outra parte, de modo que há cada vez menos razão para ficar em algum lugar (BAUMAN, 1999, p. 85). 
Uma democratização ao acesso ao saber e um poder dizer, se comunicar com outro desprovido de barreiras, facilitado pelas ferramentas eletrônicas, seria isso? Um caráter positivo e facilitador da rede na nossa relação com a linguagem: é com isso que estamos lidando? Sim e não, responderíamos, pois junto a essa "mobilidade", a esse "acesso", a esse "espaço", questões de "controle" também precisam ser pensadas. Inscrevendo, então, sócio-historicamente uma nova medida de tempo, que não é mais aquele da maturação, da espera, do tempo de cada um, mas o da pressa, e também de espaço, a internet traz consigo um imperativo de acesso, isto é, uma prescrição de que precisamos estar "conectados" o tempo todo. Chegamos num momento em que o não acesso à rede nos exclui de um "outro" mundo, num contexto em que para falarmos e para nos constituirmos como sujeitos, nós necessitamos da rede: é o mundo do lado de lá da tela, é o mundo que se constitui enquanto eu estiver "entrando", "navegando", "surfando". A tecnologia, podemos assim dizer, é extremamente absorvente e se pauta num imaginário de que não podemos viver sem ela.

Metaforicamente, podemos imaginar a rede eletrônica tal como uma "rede", que nos prende, enquanto seus sujeitos, que nos "pesca", enquanto usuários da internet. Mas, se há "rede" e há "peixes", precisam existir "pescadores" realizando tal "fisgada". É nesse momento que nos colocamos a pensar na origem dos imperativos da rede: quem seriam os grandes interessados nessa supremacia da globalização? Grandes corporações de mídia lucram com a nossa inseparabilidade da tecnologia, com máquinas, softwares, com a publicidade online, enfim, com o oferecimento de inúmeros serviços.

Podemos ainda pensar tal relação entre a rede, seus sujeitos usuários e os sujeitos interessados nesse contínuo acesso, do ponto de vista do Pan-óptico de Foucault, isto é, de sua reflexão, em sua obra Vigiar e Punir (2004), a respeito dos dispositivos disciplinares: um conjunto de disciplinas que permitiria uma vigilância e um controle social cada vez mais eficientes. Pelo IP de nossas máquinas, as grandes empresas e corporações de mídia nos rastreiam, identificando os nossos passos, os nossos acessos na rede: deixamos a todo tempo, no espaço eletrônico, marcas controláveis, que se tornam informações e que retornam a nós por meio do controle, seja oferecendo-nos produtos e serviços que condizem com nossos anseios ou podando-nos ao acesso daquilo que não nos é permitido saber. Como bem nos disse Castells (2003, p. 143), refletindo sobre a internet, os negócios e a sociedade, bem como sobre o crescimento do uso da internet como ferramenta de trabalho:

O entusiasmo com a liberdade trazida pela internet foi tamanho que esquecemos a persistência de práticas autoritárias de vigilância no ambiente que continua sendo o mais importante de nossas vidas: 0 trabalho. À medida que os trabalhadores se tornam cada vez mais 
dependentes da interconexão por computador em sua atividade, a maioria das companhias decidiu que tem o direito de monitorar os usos de suas redes por seus empregados (p. 143).

E aqui poderíamos acrescentar o ambiente doméstico, dos nossos notebooks ou celulares, da nossa própria individualidade, visto que, para além do âmbito profissional, a internet, a conexão a todo tempo e o tempo todo, o estar ligado na rede, nas notícias, nos sites de relacionamento, na caixa de e-mail, nas novidades do mundo virtual se faz uma necessidade cada vez maior e cada vez mais "compartilhada" (nos remetendo então aos sentidos da própria rede) pelos sujeitos da linguagem na era da segunda "Galáxia de Gutenberg", do imperativo da rede, comumente chamada de era da informação.

\section{O DIGITAL COMO MATERIALIDADE LINGUÍSTICO-DISCURSIVA: UMA NOVA TOPOLOGIA DE LEITURA E DE ESCRITA}

Pensar o digital como materialidade linguístico-discursiva nos remete aos conceitos de texto, intertexto e hipertexto, no contexto dos estudos da língua e, especialmente, ao ponto de vista da Análise de Discurso, o qual nos leva a refletir sobre a rede eletrônica como um espaço em que uma nova topologia de leitura e de escrita se inaugura. Um texto é definido por duas perspectivas complementares, quais sejam por sua "organização ou estruturação que faz dele um 'todo de sentido" ou por sua condição de "objeto de comunicação que se estabelece entre um destinador e um destinatário". O texto só tem existência quando pensado nessa dualidade que o constitui: "objeto de significação e objeto de comunicação", de modo que seu estudo, no campo da Semiótica e, desse modo, na perspectiva da $\mathrm{AD}$, uma teoria que bebe dessa fonte, precisa levar em conta tantos os mecanismos internos, linguísticos, quanto os mecanismos externos, sócio-históricos, que o define (BARROS, 1990, p.7).

Longe então da ideia de um amontoamento de frases ou de enunciados autônomos, o texto se constitui, do ponto de vista da $\mathrm{AD}$ como "uma unidade de significação em relação à situação" (ORLANDI, 2010, p. 11), demarcando-se como tal pelo fato de significar, e se apresentando como espaço de materialização do discurso, se estabelecendo, desse modo, como o objeto sobre o qual o analista se debruça buscando compreender "como o texto organiza a relação da língua com a história no trabalho significante do sujeito em sua relação com o mundo" (ORLANDI, 2005, p. 69). Pensando então o texto a partir dessa concepção de unidade e ao mesmo tempo questionando-a e chamando-a de ilusória, visto que para a $\mathrm{AD}$, o texto, enquanto materialidade discursiva, é atravessado pela memória, por sentidos outros, pelo já-lá, por várias formações discursivas, isto é, se constitui pela relação com outros dizeres, é que podemos pensar o conceito de intertextualidade.

Revista Letras, Curitiba, N. 92 p. 153-170, JUL/DEZ. 2015.

ISSN 2236-0999 (VERSÃo ELETRÔNICA) 
O conceito de intertexto, desse modo, diz respeito à relação que um texto estabelece com outros textos. Numa ação de retomada e numa lógica de linearidade, um texto caracterizado pela intertextualidade só pode ser compreendido se os textos, se os sentidos aos quais ele faz referência forem acessíveis ao seu leitor. Desse modo, a intertextualidade diz respeito ao diálogo entre textos em seus processos de produção, construção ou transformação como sistemas de produção do sentido. Pensada por Bakhtin através do conceito de polifonia, a intertextualidade corresponde às "vozes" internas "que falam e polemizam no texto, nele produzindo diálogos com outros textos" (BARROS, 1994, p. 4).

E como podemos pensar então o hipertexto, forma linguística assumida pelos dizeres constitutivos da rede eletrônica? Diferentemente da lógica linear característica da cultura escrita, isto é, do texto e do intertexto, que como lugares em que a referência a um outro dizer é sequencial e alcançável, a qualidade do hipertexto é da ordem do não-linear que se explica pela própria alegoria à rede pela qual definimos o ciberespaço: o hipertexto pode ser pensado como um lugar em que "milhões" de textos estão interconectados, como um texto galáctico, que se articula, nele mesmo, com inúmeras passagens. Falando sobre a "Galáxia de Gutenberg", livro de Marshall McLuhan, da década de 60 , que "declarava que a maneira linear de pensar, respaldada pela invenção da imprensa, estava em via de ser substituída por um modo mais global de percepção e de compreensão, por meio de imagens de TV ou de outros tipos de aparelho eletrônico", Eco (2003) denomina o advento da internet como uma "segunda galáxia" e afirma que

o produto da máquina não é mais linear: é uma explosão de fogos de artifício semióticos. Seu modelo é menos uma linha reta do que uma verdadeira galáxia, onde todos podem captar nexos inesperados entre estrelas diferentes para formar uma nova imagem celestial em qualquer novo ponto de navegação.

Aquela organização linear que rege o nosso mundo é, pois, pelo hipertexto, quebrada: a rede, a galáxia de articulações que o ciberespaço proporciona, não segue uma sequência concreta e organizada, mas, ao contrário, depende de quem, de onde e de como acessamos esse lugar. Um espaço em que ler e escrever se reconfiguram, indo além da lógica do livro, em que uma página termina depois de certo número de linhas e então temos que virá-la, em que o acesso a algo mais sobre os sentidos e os dizeres que nos interessam exige uma busca em outro lugar, talvez num outro livro na estante ou na biblioteca. Um lugar em que as páginas se atualizam a todo instante, se apresentando como "sem fim"; em que os textos estão mais que interligados, estão interconectados, em que um link nos remete num 
instante a outro lugar, a outros textos, a outros sentidos, a outros espaços discursivos: eis ai uma nova topologia de leitura e de escrita inaugurada pela rede eletrônica.

\section{Michel Pêcheux e a Análise de Discurso: um ponto de vista DISCURSIVO SOBRE O SUJEITO E OS SENTIDOS}

"o discurso me parece, em Michel
Pêcheux, um verdadeiro nó. Não é ja-
mais um objeto primeiro ou empírico.
É o lugar teórico em que se intrincam
literalmente todas as suas grandes
questões sobre a língua, a história e
o sujeito" (MALDIDIER, 2003, p. 15).

A Análise de Discurso de "linha" francesa, referencial teórico que orienta nossos estudos e nossas pesquisas, surgiu na França, na década de 60, tendo como seu maior expoente Michel Pêcheux (1938-1983), o qual inicia uma importante reflexão acerca da atividade de leitura e de escrita, de modo a desnaturalizar tais práticas, isto é, compreendê-las não mais como atividades naturais e possíveis tão-somente através do acesso ao "código" escrito. Pêcheux, desse modo, destitui a afirmativa positivista de linguagem que diz que se eu conheço determinada língua, se eu estou alfabetizado, eu consigo ler, interpretar ou compreender qualquer coisa que nela esteja escrito.

Inaugurando então um novo ponto de vista para as práticas de leitura, a $\mathrm{AD}$ se institui a partir da busca por articular a riqueza de diferentes áreas do conhecimento, quais sejam a Linguística, enquanto "teoria dos mecanismos sintáticos e dos processos de enunciação", a partir dos postulados de Saussure, o materialismo histórico, como "teoria das formações sociais e suas transformações", por meio da leitura de Althusser e a ideia de inconsciente, pensada através das contribuições de Lacan. Surge então a "teoria do discurso, como a teoria da determinação histórica dos processos semânticos": uma teoria mais ampla de linguagem, em que os discursos, apesar de alicerçarem-se num mesmo sistema linguístico, não são os mesmos, pois não correspondem a uma legítima expressão do pensamento, mas imbricam questões socioideológicas e históricas constituintes de todo dizer (ZANDWAIS, 2009, p. 26).

E o que é esse tal discurso pelo qual AD se interessa? O discurso é compreendido como o instrumento linguístico de mediação entre o homem e a realidade. Ele engloba tanto os enunciados pertencentes a uma mesma formação discursiva, quanto suas condições de produção, sendo que estas dizem respeito aos contextos, imediato ou individual (contexto em sentido estrito, significando o aqui e o agora do dizer), e histórico (contexto em 
sentido lato, mais amplo que o primeiro, considerando os aspectos sociais, históricos e ideológicos do contexto de enunciação), que possibilitam a produção do dizer. Embora precise da língua para ter existência, o discurso se estabelece como um objeto que vai mais adiante dela, já que compreende as posições socioideológicas dos sujeitos implicados em determinado dizer. Desse modo, a AD

não trabalha com a língua enquanto um sistema abstrato, mas com a língua no mundo, com maneiras de significar, com homens falando, considerando a produção de sentidos enquanto parte de suas vidas, seja enquanto sujeitos seja enquanto membros de uma determinada forma de sociedade. (ORLANDI, 2005, 15-16).

A Análise de Discurso concebe a língua, desse modo, na sua relação com o sujeito, a história e a ideologia, e sustenta a ideia de que falante e ouvinte realizam simultaneamente o processo de significação e, no lugar de uma mensagem, têm como objeto o próprio discurso, espaço em que sujeitos e sentidos se constroem conjuntamente. "As relações de sujeitos e sentidos e seus efeitos são múltiplos e variados. Daí a definição de discurso: o discurso é efeito de sentidos entre locutores" (ORLANDI, 2005, p. 21). Relacionado ao conceito de discurso encontra-se o de sentido, o qual é entendido como um efeito de sentidos entre sujeitos manifestando-se por meio do uso da linguagem, e se pauta na ideia de que os sentidos das palavras vão muito além daqueles dicionarizados, revelando marcas históricas e ideológicas de produção do dizer. Nas palavras de Pêcheux (2009, p. 146),

o sentido de uma palavra, de uma expressão, de uma proposição, etc., não existe "em si mesmo" (isto é, em sua relação transparente com a literalidade do significante), mas, ao contrário, é determinado pelas posições ideológicas que estão em jogo no processo sócio-histórico no qual as palavras, expressões e proposições são produzidas (isto é, reproduzidas).

O sujeito discursivo, nessa teoria, não corresponde a um ser humano específico, mas a um ser social, interpelado pela ideologia e que só pode ser apreendido em determinado contexto sócio-histórico. Ele é marcado por uma postura polifônica (formado por um conjunto de outras vozes) e heterogênea (marcado por diferentes discursos) os quais se negam, contradizem e convergem entre si. "A voz desse sujeito revela o lugar social; logo, expressa um conjunto de outras vozes integrantes de dada realidade social; de sua voz ecoam outras vozes constitutivas e/ou integrantes desse lugar sócio-histórico" (FERNANDES, 2005, p. 34).

O sujeito é ainda constituído pelo atravessamento de múltiplas formações discursivas, ou seja, ele é marcado por dizeres precedentes, que lhe dão a ilusão de ser a origem de seu dizer. A formação discursiva 
corresponde assim a tudo aquilo que pode e deve ser dito em determinado contexto sócio-histórico, sendo marcada por sentidos que sempre voltam, por enunciados que se repetem, que retomam uma mesma escolha temática (FOUCAULT, 2009). Ao falar de determinada formação discursiva, o sujeito o faz tendo como base uma formação imaginária criada a respeito de seu objeto discursivo, a qual está relacionada ao conjunto de representações que o sujeito faz de si e dos outros, em especial de seu interlocutor, representações estas que serão determinantes na construção de sentidos pelo sujeito. Toda formação discursiva tem ainda subjacente uma formação ideológica, visto que todo signo é marcado pela ideologia - esta entendida como um mecanismo de naturalização dos sentidos que constitui o sujeito e materializa-se através do discurso. É por meio da formação ideológica que o indivíduo é interpelado em sujeito, de maneira que ele só pode dizer aquilo que diz pelo fato de ocupar tal posição. Pêcheux (2009, p. 147) nos diz que

as palavras, expressões, proposições, etc., mudam de sentido segundo as posições sustentadas por aqueles que as empregam, o que quer dizer que elas adquirem seu sentido em referência a essas posições, isto é, em referência às formações ideológicas nas quais essas posições se inscrevem

A noção de memória discursiva, por sua vez, é pensada pelo conceito de interdiscurso, sendo que este é entendido como o "entrelaçamento de diferentes discursos, oriundos de diferentes momentos da história e de diferentes lugares sociais" (FERNANDES, 2005, p. 49). Ela diz respeito aos sentidos construídos sobre, a tudo aquilo que já foi dito em outro lugar e independentemente, e que influencia na produção discursiva do sujeito. 0 interdiscurso, nesse ponto de vista, corresponde àqueles sentidos (o já-dito) que o sujeito acessa na formulação de seu discurso e na interpretação de outros dizeres. O sujeito, entretanto, não tem autoridade sobre a forma como os sentidos lhe afetam, contudo é a ideologia que naturaliza tais sentidos, criando o efeito de sentido de evidência e fazendo parecer natural que seja assim.

Imbricado ao conceito de interdiscurso é que Pêcheux (1997) desenvolve duas ilusóes ou esquecimentos do sujeito. $\mathrm{O}$ esquecimento $\mathrm{n}^{\circ} 1$ está relacionado crença do sujeito de que ele é a origem do dizer, sendo que "o sujeito não reconhece a inclusão daquilo que ele diz em determinada formação discursiva e não em outra, uma vez que é interpelado pela ideologia" (PACíFICO, 2002, p. 31). O esquecimento $\mathrm{n}^{\circ} 2$, por sua vez, é determinado pela ilusão da literalidade, ou seja, pela certeza que o sujeito tem em relação à ideia de que tudo aquilo que ele diz corresponde ao que ele pensa e que seu discurso só pode ser enunciado daquela maneira. 
Finalizando este tópico acerca da teoria que nos move, trazemos o conceito de arquivo que, complementando as noções de memória e interdiscurso, corresponde a todo o campo de documentos pertinentes a uma dada questão (PÊCHEUX, 1997), o qual se pode definir como uma memória documental, mais abrangente então que a memória discursiva, mas condicionada a esta a fim de que o sujeito possa acessar novos sentidos.

\section{Sujeitos E SEnTidos SOBRE A DocÊNCIA NO ESPAÇO DA REDE ELETRÔNICA}

O curso de graduação em Pedagogia concebe aos seus licenciados, além da habilitação para a gestão escolar, a capacitação para o magistério tanto da Educação Infantil quanto dos anos iniciais do Ensino Fundamental. Tal característica, isto é, a existência (e exigência, no caso das escolas) de uma formação comum para o trabalho com etapas diferentes, entretanto, subsequentes da educação básica, indica uma integração e uma complementariedade entre os trabalhos pedagógicos desenvolvidos nessas etapas de ensino. Essa formação comum de que falamos leva-nos a pensar que a docência de crianças pequenas, no espaço da educação infantil, e o ensino no contexto do fundamental precisariam "movimentar" sentidos semelhantes no contexto escolar e, principalmente, no discurso de sujeitos-professores. Contudo, nossa experiência de trabalho no contexto escolar tem evidenciado que sentidos distintos são enunciados sobre tais etapas de ensino e, mais que isso, que sentidos que dizem respeito à desqualificação do trabalho pedagógico desenvolvido na educação infantil são criados, apropriados e reiterados pela por inúmeros sujeitos que se imbricam ao contexto escolar, especialmente pelos próprios sujeitos-professores. No âmbito da escola, nos deparamos com um discurso que distingue os professores de creche, pré-escola e ensino fundamental, inabilitando aqueles que ainda não têm a alfabetização como objetivo pedagógico a ser alcançado.

Nossa identificação com os referenciais teóricos da Análise do Discurso francesa - que já pudemos retomar alguns conceitos-chave - e da teoria do letramento de Tfouni (2006) nos mobiliza em torno dos sentidos sobre a docência produzidos no interior da escola e nos instiga à compreensão da relação entre tais sentidos e as concepções de linguagem, alfabetização e letramento dos sujeitos-professores. Tal objetivo de pesquisa surge a partir de uma experiência nossa de ensino que demonstra existir, no contexto escolar, uma legitimação discursiva de que é a "prática da alfabetização" quem vai caracterizar um ambiente escolar como "pedagógico" e, além disso, que vai definir o sujeito responsável por determinada etapa de ensino como "professor".

É a partir da teoria da "grande divisa", inaugurada por Street (1989), segundo a qual há uma separação radical entre os usos orais e os 
usos escritos da língua que pretendemos, no contexto de nosso trabalho de pesquisa, analisar a argumentação no discurso de sujeitos-professores sobre suas práticas e concepções de trabalho com a linguagem, na busca por entender porque, apesar de concepções mais amplas de trabalho com linguagem já se fazerem presentes nos documentos legais de referência às diversas etapas de ensino de nosso país, sentidos de complementariedade entre as práticas desenvolvidas na educação infantil e no ensino fundamental ainda não constituem o discurso de sujeitos-professores.

A fim de estabelecer uma relação entre os estudos sobre a rede eletrônica que aqui desenvolvemos e as questões de nossa pesquisa que até aqui arrolamos, fizemos, pois, uma busca por espaços de enunciação possíveis aos sujeitos-professores na rede, identificando sentidos e sujeitos se posicionando discursivamente com relação ao trabalho pedagógico desenvolvido na educação infantil. Nesse momento, queremos então trazer alguns recortes e analisá-los do ponto de vista do sujeito e dos sentidos, identificando formações discursivas e, quem sabe ainda, (re)pensando o espaço da rede enquanto lugar de enunciação sobre a docência. São dois os espaços virtuais que aqui evocamos: o primeiro deles uma postagem numa rede social, em que uma charge que se apresenta pelo efeito de sentido de "luta por direitos" se remete à necessidade de reafirmar o espaço da educação infantil como lugar "sim" de professores, e o segundo, um blog sob o título de espaço de debate entre professores de educação infantil, que se pauta em questões políticas sobre a carreira docente.

Recorte $1, \log$ abaixo.

Figura 1 - "Professores da Educação Infantil"

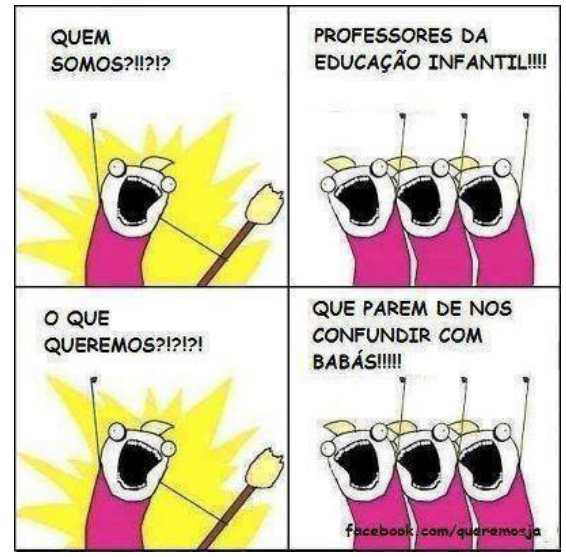

Fonte: Profissão Professor, 2015. 
Recorte 2:

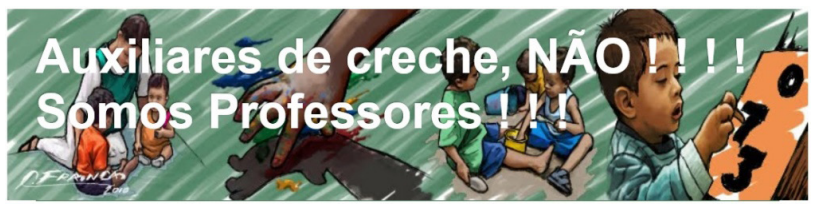

Figura 2 - "Auxiliares de creche, NÃO!!!"

Fonte: Blog Professores..., 2015.

Os recortes 1 e 2 , respectivamente relacionados aos dois espaços da rede que citamos, nos permitem pensar que a temática da docência no âmbito da educação infantil se configura por sentidos políticos: nos remete então a uma formação discursiva de luta, isto é, a uma inscrição dos sujeitos-professores num discurso perpassado pelo desejo de fazer cair um imaginário social de desvalorização do trabalho dos professores de educação infantil - o que pensamos se relacionar à sentidos históricos de constituição das creches e pré-escolas, enquanto um espaço em que inicialmente foi pensado em moldes assistencialista ou como um espaço de trabalho para o feminino (CERISARA, 1996). No primeiro recorte o sujeito parece "gritar" querendo destituir um rótulo de babá que imaginariamente opera no discurso de sujeitos outros, formação ideológica esta que podemos perceber por meio dos recortes abaixo, os quais correspondem a comentários de sujeitos da rede a essa publicação:

Recorte 3:

"é babá siiiiiiiiiim. :)"2

Recorte 4:

"Ueeeee ... Nao sao?"

Questionando a defesa de reconhecimento profissional que a charge faz emergir e demarcando (aqui pensando na intensidade que as marcas linguísticas de repetição nos deixam) a posição do professor de educação infantil como uma prática que se equipara "sim" ao trabalho de uma babá, os recortes 3 e 4 são enunciados por sujeitos da rede que não ocupam a posição discursiva de sujeitos-professores, e reforçam uma ideologia domi-

2 Os recortes de 3 a 10, e o recorte 13, se referem a comentários de sujeitos à publicação da página "Profissão Professor" no Facebook, apresentada no recorte 1 (PROFISSÃO PROFESSOR, 2015). 
nante que caracteriza o trabalho da educação infantil como espaço apenas de "cuidado", destituído de caráter pedagógico. E o que dizem os próprios sujeitos-professores?

Recorte 6:

"O que eu mais desejo é que se entenda a importância deste grau de ensino".

Recorte 7:

"sobe um ódio quando falam: ah, vc é tia de creche? que legal, cuidar de criancinhas... Cara, somos PROFS!"

Recorte 8:

"Os pais acham isso mesmo. Eles acham que somos escravas".

Recorte 9:

"Ha ha ha bem vdd algumas mães até exageram, mas gosto qdo elas (as crianças) chegam com dengo perto de mim, meus bbs".

Recorte 10:

“de certa forma, é o q somos...".

É trazendo os sentidos de desvalorização de suas práticas como característico do imaginário social e a consciência da importância da educação como um conceito ainda bem distante da maioria dos sujeitos que se relacionam com a escola, tais como pais que consideram professores como "escravos" ou que acreditam que "a tia da creche" se dedica apenas a "cuidar de criancinhas", que os recortes 7,8 e 9 se apresentam. No entanto, é de um modo distinto que os sujeitos-professores dos recortes 9 e 10 parecem enunciar, se colocando num entremeio de formações discursivas: ao mesmo tempo, em que parecem se identificar com os sentidos de luta por reconhecimento de sua atuação docente, tais sujeitos se inscrevem num outro lugar discursivo, isto é, junto aos sentidos de questionamento sobre a pertinência da causa em torno de se diferenciar professores da educação infantil e babás, o que podemos perceber pela referência aos alunos como "meus bebês" ou pela marca linguística de dúvida que o trecho "de certa forma" traz para a discussão, podendo assim quem sabe equiparar àqueles dois lugares questionados.

É num movimento semelhante que nos deparamos na análise das publicações do blog. Se apresentando então como um espaço para discussão 
sobre as causas docentes, o blog realiza várias publicações sobre a temática da educação infantil, especialmente no que diz respeito ao reconhecimento legal dos seus profissionais como professores - reconhecimento esse que nossas experiências de ensino permitem dizer que é ainda, em sua maioria, uma causa política e não uma realidade - trazendo situações de diferentes redes de ensino e prefeituras do país. Numa publicação sobre uma mudança de nomenclatura de uma cidade do Rio de Janeiro, nos deparamos com dois discursos de sujeitos-professores que nos remetem então às formações discursivas de que já falávamos:

Recorte 11:

"E esse é todo o trabalho que desempenhamos, e além de trocarmos fralda (que acaba ser comprovado que é uma atribuição de professor) quem conhece of funcionamento de uma creche sabe que deste o berçário há um trabalho pedagógico que é desenvolvido com as crianças"

\section{Recorte 12:}

"Vocês fizeram concurso para um cargo mais fácil de passar na prova e agora querem uma ascensão inconstitucional??? Assim é mole, colega: faço concurso para um cargo menos visado, mais fácil e com salário menor e, depois, brado aos quatro ventos que exerço, na verdade, atribuiçóes de outro cargo e exijo que o Estado transponha-me para outro cargo (com menor carga horária e maior salário )".

De um lado temos um sujeito-professor que toma como seus os sentidos da causa defendida no blog e busca argumentos que para validar a sua afirmação de que a educação infantil é um espaço pedagógico, dizendo que "acaba de ser comprovado" que "trocar fralda" é uma "atribuição de professor". De outro um sujeito-professor que, apesar de compartilhar os sentidos de formação profissional com os sujeitos que se unem à causa, já que se marca como professor das séries iniciais, chama de "ascensão institucional" o que os outros sujeitos identificam como "luta política". Um discurso em torno da charge e da postagem do blog que vai de uma formação discursiva a outra, que está aqui, junto à causa, ao mesmo tempo em que está lá, condenando-a: é assim que percebemos os sentidos enunciados pelos próprios sujeitos-professores sobre a docência. Seria, pois, esse efeito do Rio de Janeiro (BLOG PROFESSORES..., 2015). 
de movência, de ir e vir do dizer e dos sentidos, encorpado pelo próprio efeito galáctico da rede eletrônica? Tal interrogação nos remete à rede social do primeiro recorte, em que sujeitos e mais sujeitos-professores são "marcados" (numa espécie de link, que os "prendem" àquele dizer) por seus contatos da rede e "convidados" a se identificar (ou "curtir", na linguagem da rede) com os sentidos que a charge evoca. A rede ainda permite ao sujeito "argumentar" (o que ela chama de "comentar") sobre a questão, se posicionando em relação ao discurso de sujeitos outros, mesmo que estes não sejam seus contatos. É o caso do dizer que agora trazemos, o qual é produzido por um sujeito-professor como resposta a um comentário de outrem que sugere que se o mesmo quiser ter reconhecimento profissional precisa estudar ou então lecionar noutra modalidade de ensino.

\section{Recorte 13:}

A questão não é estudar ou não, para trabalhar com os pequenos também tem que estudar: faculdade, pós-graduação, especializações sempre! E, claro, na educação infantil o cuidado deve existir com toda a certeza, mas o nosso trabalho vai muito além do cuidado, justamente porque estudamos e somos capacitadas para ser professoras, babá qualquer uma pode ser, professora não. Mas lógico que muitas vezes desempenhamos o papel de tia, mãe, avó, até porque muitas vezes, as crianças passam mais tempo com as professoras do que com os pais... A questão não é nem as crianças nos chamarem de tias, isso é normal. A questão é os outros que não valorizam como profs.

Um sujeito identificando com seu dizer, posicionando-se discursivamente e argumentando sobre os seus sentidos: podemos então pensar o espaço da rede como lugar de tudo poder dizer e afirmar que é por meio da autoria que sujeitos-professores fazem uso desse espaço de enunciação? Uma charge "compartilhada", ou melhor dizendo, "(re)produzida" por 5.160 usuários da rede, e "curtida", ou diríamos, "fazendo sentido", para mais 2.786 deles, mas "comentada", isto é, usada como espaço de produção de sentidos pelos sujeitos, por somente 176 , assim como um blog em que a maioria dos comentários, seja contra ou a favor das publicações apresentadas, se dá na condição de anonimato, nos levam questionar até que ponto discursivizar sobre a atuação profissional no âmbito da educação se faz um sentido possível (ou permitido) no contexto da rede eletrônica.

Um ir e vir que representa os sentidos e as inscrições discursivas dos sujeitos-professores de nossa pesquisa ou que reflete efeitos do próprio contexto da rede? O ciberespaço enquanto espaço de posicionamento, argu- 
mentação e autoria dos sujeitos-docentes ou como um lugar arriscado para se falar sobre profissão, já que coloca em evidência, e aos olhos de todos, as causas e os sentidos que movem os sujeitos-docentes? São questões em nós incitadas por esse momento de reflexão e que se colocam premissas para nossas futuras investigações.

\section{CONSIDERAÇÕES FINAIS}

Foi buscando cumprir o propósito de retomar algumas reflexões sobre o sujeito discurso e a rede eletrônica que nos arriscamos na retomada dos conceitos da Análise de Discurso e das recentes discussões sobre a rede eletrônica enquanto um espaço discursivo que instaura uma nova medida de tempo e de espaço, e uma nova topologia de leitura e de escrita.

Nosso movimento de análise, de modo complementar, pretendeu conhecer os discursos e identificar os sentidos produzidos por sujeitos-professores no espaço da rede eletrônica, pensando as formações discursivas pela qual os seus dizeres em relação à docência se constituem. Longe de propor conceitos ou de realizar conclusões, as discussões trazidas se fizeram lugar de reflexão nosso objeto de pesquisa, o qual se encontra em fase inicial, querendo suscitar questões e sentidos em torno do sujeito-professores, dos sentidos sobre a docência e do ciberespaço.

\section{REFERÊNCIAS}

ASSEF, A. E. C.; PACÍFICO, S. M. R. Sujeitos-professores e autoria: Que lugar é esse? Entremeios revista de estudos do discurso, n. 4, jan. 2012.

BARROS, D. L. P. Dialogismo, polifonia e enunciação. In: BARROS, D. L. P.; FIORIN, J. L. (Orgs.). Dialogismo, Polifonia, Intertextualidade em torno de Bakhtin. São Paulo: Editora da Universidade de São Paulo, 1994. p. 1-10.

Teoria semiótica do texto. São Paulo: Ática, 1990.

BAUMAN, Z. Globalização: as consequências humanas. Tradução de Marcus Penchel. Rio de Janeiro: Jorge Zahar, 1999.

BLOG PROFESSORES DE EDUCAÇÃO INFANTIL. Disponível em: < http://professoresdeeducacaoinfantil. blogspot.com.br/>. Acesso em: 20 dez. 2015.

CASTELLS, M. A galáxia da internet: reflexões sobre a internet, os negócios e a sociedade. Rio de Janeiro: Jorge Zahar Editor, 2003.

CERISARA, A. B. A construção da identidade das profissionais de educação infantil: entre o feminino e o profissional. Tese (Doutorado em educação) - Faculdade de Educação, USP, São Paulo, 1996.

ECO, U. Muito além da internet. 2003. Disponível em: <http://www.ofaj.com.br/textos_conteudo. php?cod=16>. Acesso em: 20 dez. 2015.

FERNANDES, C. A. Análise do discurso: reflexões introdutórias. Goiânia: Trilhas Urbanas, 2005. 
FOUCAULT, M. A arqueologia do saber. 7. ed. Rio de Janeiro: Forense Universitária, 2009.

Vigiar e punir: nascimento da prisão. Petrópolis: Vozes, 2004.

MALDIDIER, D. A inquietação do discurso: (re)ler Michel Pêcheux hoje. Tradução de Eni Orlandi. Campinas: Pontes, 2003.

ORLANDI, E. P. A contrapelo: incursão teórica na tecnologia - discurso eletrônico, escola, cidade. Revista Rua, Campinas, n. 16, v. 2, nov. 2010.

Análise de discurso: princípios e procedimentos. 6. ed. Campinas, SP: Pontes, 2005.

PACÍFICO, S. M. R.; ROMÃO, L. M. S. (Orgs.). Leitura e escrita: no caminho das linguagens. Ribeirão Preto, SP: Alphabeto, 2007.

PACÍFICO, S.M.R. Argumentação e autoria: o silenciamento do dizer. Tese (Doutorado em educação) - FFCLRP/USP, Ribeirão Preto, 2002.

PÊCHEUX, M. A propósito da Análise Automática do discurso: atualização e perspectivas (1975). In: GADET, F.; HAK, T. (Orgs.). Por uma análise automática do discurso: uma introdução à obra de Michel Pêcheux. 3 ed. Campinas, SP: Unicamp, 1997.

Semântica e discurso: uma crítica à afirmação do óbvio. Tradução de Eni Puccinelli Orlandi et al. 4. ed. Campinas, SP: Editora da Unicamp, 2009.

POSSIDÔNIO, J. A. A argumentação no discurso de professores sobre a "grande divisa" entre a Educação Infantil e o Ensino Fundamental. Projeto de Pesquisa (Programa de Pós-graduação em Educação) FFCLRP-USP, Ribeirão Preto, SP, 2013.

Os sentidos sobre família e o indício da subjetividade no discurso de sujeitos-alunos do Ensino Fundamental. Trabalho de Conclusão de Curso (Licenciatura Plena em Pedagogia) - FFCLRP-USP, Ribeirão Preto, SP, 2011.

PROFISSÃO PROFESSOR. Disponível em: < https://www.facebook.com/pages/Profiss\%C3\%A3o-Professor/329222423788535>. Acesso em: 20 dez. 2015.

ROMÃO, L. M. S.; PACÍFICO, S. M. R. Era uma vez uma outra história: leitura e interpretação na sala de aula. São Paulo: DCL, 2006.

TFOUNI, L. V. Letramento e Alfabetização. 8. edição, São Paulo: Cortez, 2006.

ZANDWAIS, A. Perspectivas da análise do discurso fundada por Michel Pêcheux na França: uma retomada de percurso. Santa Maria: UFSM, Programa de Pós-graduação em Letras, 2009.

Submetido em: 10/06/2015

Aceito em: 13/10/2015 